\title{
Ethics and Nursing Practice
}

\section{A case study approach}

Ruth Chadwick B.Phil., MA, D.Phil., LLB

Director, Centre for Applied Ethics

Philosophy Section

University of Wales College of Cardiff

and

Win Tadd B.Ed.(Hons), DN, RGN, SCM, ONG, RCNT, Cert.Ed., RNT

Senior Teacher and Project Officer, Project 2000

Gwent Health Authority 
(C) Ruth Chadwick \& Win Tadd 1992

Softcover reprint of the hardcover 1st edition 1992

All rights reserved. No reproduction, copy or transmission of this publication may be made without written permission.

No paragraph of this publication may be reproduced, copied or transmitted save with written permission or in accordance with the provisions of the Copyright, Designs and Patents Act 1988 or under the terms of any licence permitting limited copying issued by the Copyright Licensing Agency, 90 Tottenham Court Road, London WIP 9HE.

Any person who does any unauthorised act in relation to this publication may be liable to criminal prosecution and civil claims for damages.

First published 1992 by

MACMILLAN EDUCATION LTD

Houndmills, Basingstoke, Hampshire RG21 2XS

and London

Companies and representatives

throughout the world

ISBN 978-0-333-52045-1 ISBN 978-1-349-11388-0 (eBook)

DOI 10.1007/978-1-349-11388-0

A catalogue record for this book is available from the British Library

\section{Acknowledgements}

The publishers would like to thank the following for permission to use photographs: Camera Press p.140; Nigel Dickinson/Leader Photos p.96; Michelle Jones p.37; Caroline Marden pp.80, 111; John Millar pp.17, 65, 151; Rex Parry p.49; Paul Reas/Network p.164.

Every effort has been made to trace all the copyright holders but if any have inadvertently been overlooked the publishers will make the necessary arrangements at the first opportunity. 


\section{Contents}

Foreword

Acknowledgements

iv

Introduction

vi

vii

\section{PART I}

Chapter 1: Ethics and professional codes 3

Chapter 2: The nurse-patient relationship 17

Chapter 3: The nurse-nurse relationship 37

Chapter 4: The nurse-doctor relationship 49

\section{PART II}

Chapter 5: Nursing adults 65

Chapter 6: Nursing the unborn and newborn $\quad 80$

Chapter 7 : Nursing the child 96

Chapter 8 : Nursing mentally ill people 111

Chapter 9 : Nursing people with a mental handicap 127

Chapter 10 : Nursing people with AIDS 140

Chapter 11 : Nursing elderly people 151

Chapter 12: Nursing the dying person 164

Conclusion 182

Appendices: Nursing codes of practice for the USA, the International Council of Nurses and the UK

Glossary

Suggestions for further reading 


\section{Foreword}

One of the special privileges which comes with a request to write the foreword for a book written by someone else is that you are necessarily granted the opportunity to read the manuscript after it has been completed but before its publication. Such a privilege has been mine on several previous occasions. Never has the privilege been as great or the benefits from the preparatory reading so significant as on this occasion.

In the course of my role as a senior member of staff for the statutory body which regulates the nursing, midwifery and health visiting professions in the UK, I meet many practitioners in their respective practice settings, converse with many others when participating in conferences or presenting seminars and respond to the letters and telephone calls of a steadily increasing number. In a majority of such cases the issues that the individual practitioners wish to raise, but have not felt able to raise with colleagues or professional managers in their own settings, are concerned with the ethics of professional practice. Their hesitation to engage in local discussion is usually based on the fact that they are unsure of their ground because, even though they have endeavoured to become informed about ethical principles, if they have found any relevant reading material it has not seemed to address the essentially practical issues which concern them.

I am not intending to suggest that there is a gap in the market for a book that tells the practitioner what to do in a specific set of circumstances. Quite the reverse. Professional practice involves making judgements in a wide variety of circumstances, and being accountable for those judgements.

What I believe to be important, however, is that, before coming face-to-face with a given type of dilemma, practitioners should have had the opportunity to understand and consider the ethical principles that underlie professional practice. One of the most effective ways of doing this is through the use of case studies that provide examples of such dilemmas and open commentary upon them. 
I believe that the reader will find, as I have already found, that this book provides not only the means of understanding the theory but of arriving more easily at the solutions to the dilemmas they encounter.

The authors refer, in the opening sentence of their introduction, to the increasing interest in health care ethics. I share their pleasure in that increase and welcome the fact that they have produced such an accessible and informative volume in response to the demand for information that they have identified.

Reginald H. Pyne

Assistant Registrar, Standards and Ethics

United Kingdom Central Council for Nursing Midwifery

and Health Visiting 


\section{Acknowledgements}

We are indebted to numerous people who, in their various ways, have helped us to write this book. We would first like to thank each and every one of the nurses who shared their experiences of and concerns about nursing practice and without whom this book would not have been possible.

Second, we are grateful to the staff of the Hastings Centre, New York, where, as International Fellows, we were welcomed, encouraged, enabled to research, and involved in lively discussion about many of the issues addressed in this volume.

Although it is not possible to mention everyone at the Centre by name, there are two people in particular who deserve special attention and thanks. Strachan Donnelly, Director of Education, who made our visit possible in the first place and who made lunch-times so memorable. Also, Marna Howarth, Librarian, whose kindness and patience was shown by her tireless assisting with our research, and also on many trips to the supermarket. We shall never forget their help.

Next we would like to thank Dr Lillie Shortridge, Professor and Assistant Dean of Lienhard School of Nursing, Pace University for the time that she devoted to us and her willingness to provide access to postgraduate nurses undertaking a Masters programme.

We are grateful to those nurses on the programme who took time from their studies to provide us with material and, in so doing, brought new dimensions to the book.

Our thanks, too, to Rex Parry and Peter Murby at Macmillan for their advice, understanding and undying patience in the preparation of this volume.

Finally, we would like to thank our partners and families: Stephen Copley for his sense of humour and determination that we should finish; Vic Tadd for his patient reading, helpful comments and endless support and Rebecca and Andrew who were so very understanding when their mother was otherwise engaged. 


\section{Introduction}

In recent years, there has been increasing interest in health care ethics. Texts, conferences and courses on medical, bio-ethics and indeed nursing ethics are becoming commonplace.

In part, this has been due to advancing scientific and medical technology which has resulted in previously unimaginable treatment possibilities being made available. To a large extent this has resulted in the idea that the ethical issues in health care today are primarily medical and, thus, concern only doctors.

However, this view is being increasingly challenged as professional roles and boundaries are being called into question more often, and because receivers of health care are demanding more involvement in the decisions that often radically affect their lives.

The traditional role of the nurse, as one of exclusively carrying out doctors' orders, is also under scrutiny. Today, many nurses perceive that they have an important role to play in undertaking specific nursing activities, other than those prescribed by medical staff, as well as ensuring that the interests of the patient or client are kept to the fore in all decision-making.

In this volume we hope to show moral principles at work in their application to the sort of real life problems faced by nurses every day. The stimulus for collecting the cases originated from the depth of feeling and concern expressed by many nurses to one of the authors in her work as a nurse teacher.

This led to research, using a critical incident technique, being undertaken with over $400 \mathrm{UK}$ nurses, many of whom were students undertaking pre-registration courses, and some 50 or so qualified nurses undertaking a Master in Nursing course in the USA, to discover the common ethical issues that they faced in their day-to-day practice in the context of today's health care settings.

The point of the exercise is not to say what we, as authors, think about the particular dilemmas. The two of us might not necessarily agree. In some cases the judgement of the writer on a case is made clear, while in others it is not. This in itself is not important. The discussion of the cases is meant to provide a springboard for discussion of the ideas expressed, or 
a target against which to argue. Nurse teachers may well find the cases useful source material for teaching ethics on both pre- and postregistration courses and individual nurses reading the cases will see how one might approach an ethical dilemma or problem.

Whichever way the book is ultimately used, we hope that it will be of assistance to nurses in tackling the difficult situations which they are likely to face in the course of their work. This may in some small way reduce the tension and stresses that nurses face on an almost daily basis, not only by making their work more rewarding and fulfilling, but also by improving and increasing the quality and humaneness of care afforded to the patient.

The incidents are recounted in the nurses' own words and, again, we are grateful to all those nurses for their willingness that we should publish their stories. Where names of patients are used, these are fictitious to maintain confidentiality.

Some books on nursing ethics begin by presenting a fairly full and detailed exposition of different kinds of ethical theory. We have not taken this approach. Different ethical principles are introduced at various points in the text, and then shown at work in discussing the cases. Suggestions for further reading on ethical theory are provided at the end of the book for those who wish to pursue this further.

Although we do not want to suggest that there is only one 'right' answer to the problems discussed in the book, what we want to stress throughout is the importance of the principle of autonomy. There is a presumption that persons have the capacity to make decisions about their own lives, called a capacity for self-determination or for autonomy. Because of this, the principle of autonomy holds that we should respect the choices that they make (Gillon, 1985, pp. 111-25). This is part of what it means to respect persons.

Because this principle is clearest in the case of the adult, we have discussed the nursing of adults at the beginning of Part II. The adult is called the 'central case' in health care. Even there, as we shall see, there are some problem areas, but the chapters that follow are especially problematic because they deal with groups of patients or clients for whom the presumption of fully developed autonomy does not hold.

The unborn and the newborn, for example, have not yet developed this capacity, so some people argue that they should not be considered as people at all. Children gradually develop their capacity for autonomy, but problems arise about when they become fully autonomous, and to what extent their decisions about treatment should be respected. Persons with a mental handicap or illness suffer from a diminished capacity for autonomy and problems arise about the implications of that for their treatment and care. The person with AIDS still has a capacity for autonomy and is worthy of respect, but this is frequently denied because of the nature of the illness. Elderly people are sometimes thought to have lost, or to be losing their capacity for decision-making, even when there is little evidence to 
support this in individual cases, which can lead to an unwarranted paternalism - the overriding of their autonomy for what is thought to be their own good. Consideration of those who are terminally ill raises the question of the extent to which persons can retain autonomy, in the sense of control over their own lives, even in their death.

This theme runs through Part II in the discussion of the different groups of clients and patients. In Part I, we stress the importance of the autonomy of the nurse. By this we mean the nurse's capacity to think and decide about the sort of problems covered in this volume. Neither the UKCC Code of Professional Conduct (hereafter referred to as the Code of Conduct) nor other members of the health care team (e.g. senior nurses or doctors) can take away that responsibility. Part I explores the usefulness of guidance such as the Code of Conduct in moral decision-making, and the nurse's relationship with other nurses, the medical profession and the patient or client.

\section{Principles and virtues}

As well as the principle of autonomy, there will be discussions about rights, consequences, justice, among other topics. Commonly, there have been two main kinds of ethical theory-roughly, those that appeal to consequences and those which do not. Those that do appeal to consequences proceed by asking 'What will happen if $\mathrm{X}$ does this? How will it affect the interests of $\mathrm{Y}$, or the majority of people?' Those that do not, commonly appeal to some set of rules or principles for guidance, and thus avoid the difficulty of trying to predict consequences. The principle of respect for persons, and the view that people have certain rights which must be respected at all costs are of this type. Such non-consequentialist views are commonly classified as 'deontological'. They say what must be done.

The principle of autonomy can be supported by either school, but for different reasons. The non-consequentialists might argue that there is something special about persons that makes them worthy of respect and, as indicated above, to abide by the principle of autonomy is one way of showing respect for persons. The consequentialist, on the other hand, might suggest that it is in the interests of persons to have their autonomous decisions respected, and so it produces the best consequences. One reason for this is that they are quite likely to be the best judges of what is in their own interests, and another is that nothing is more likely to alienate people than having their decisions overruled by those who claim to know better.

It will become clear, however, in the course of the text, that there are several occasions when the interests of different people conflict. Then the person (in our case, the nurse) who has power to affect people's interests 
has an unenviable task. In such situations, it is difficult to see how it is possible to avoid a consequentialist calculation about how to produce the best result overall. This will involve thinking about the importance of the different interests at stake (some of which may be interests of the nurse) and how to produce the greatest possible satisfaction of interests.

In Chapter 2 we see some of the conflicts between nurses' interests and those of the patient. In this chapter, we also look at a different way of approaching ethics. Instead of discussing principles, we discuss what is known as 'virtue ethics'. Here, the suggestion is that what the good nurse should do is not simply to think about principles, but to acquire certain virtues, such as diligence and candour.

What emerges above all from the cases and the discussion about them is both the extent of and constraints upon the nurse's power to affect standards and ethics in patient care. One reason that we see autonomy as being so central, not only for patients but also for nurses, is that the autonomy of the nurse is vitally important in safeguarding the interests of patients and clients.

The convention used throughout the text, in relation to gender, is that the nurse is referred to as 'she' and others such as the patient or client as 'he', unless the discussion is about an already identified client. This is done only to avoid the use of clumsy he/she references and does not in any way indicate a value belief on the part of the authors, or indeed a lack of awareness of the growing number of male nurses.

With reference to the recipients of health care, both patient and client have been used in recognition of the fact that there is concern on behalf of some nurses to move from the term 'patient' to that of 'client'. We have, therefore, used both terms within the text to take cognisance of this factor.

\section{References}

Gillon, R. (1985) 'Autonomy and Consent', in M. Lockwood (ed.), Moral Dilemmas in Modern Medicine (Oxford: Oxford University Press). 